\title{
$\alpha$-optimal best proximity point result involving proximal contraction mappings in fuzzy metric spaces
}

\author{
Abdul Latifa ${ }^{a}$ Naeem Saleem ${ }^{b, *}$, Mujahid Abbas ${ }^{a, b}$ \\ ${ }^{a}$ Department of Mathematics, King Abdulaziz University, P. O. Box 80203, Jeddah 21589, Saudi Arabia. \\ ${ }^{b}$ Department of Mathematics, University of Management and Technology, C-II, Johar Town, Lahore - Pakistan.
}

Communicated by $\mathrm{N}$. Hussain

\begin{abstract}
In this paper, we introduce $\alpha$-proximal fuzzy contraction of type-I and II in complete fuzzy metric space and obtain some fuzzy proximal and optimal coincidence point results. The obtained results further unify, extend and generalize some already existing results in literature. We also provide some examples which show the validity of obtained results and a comparison is also given which shows that contractive mappings and obtained results further generalizes already existing results in literature. (c) 2017 all rights reserved.
\end{abstract}

Keywords: Fuzzy metric space, $\alpha$-proximal fuzzy contraction of type-I, $\alpha$-proximal fuzzy contraction of type-II, fuzzy expansive mapping, optimal coincidence best proximity point, t-norm.

2010 MSC: 47H10, 47H04, 47H07.

\section{Introduction and preliminaries}

A classical best approximation theorem [4] states that if $A$ is nonempty compact convex subset of a Banach space $X$ and $T: A \rightarrow X$ is a continuous map, then there exists a point $X^{*}$ in $A$ such that

$$
d\left(x^{*}, T x^{*}\right)=d\left(T x^{*}, A\right)=\inf \left\{d\left(x, T x^{*}\right): x \in A\right\} .
$$

A point $x^{*}$ in the above theorem is known as the approximate fixed point of $\mathrm{T}$ or an approximate solution of a fixed point equation $T x=x$.

The study of conditions that assure the existence and uniqueness of optimal approximate fixed point of mapping $T$ is an active research area. If $A$ and $B$ are nonempty subsets of a normed linear space $X$ and $T: A \rightarrow B$. A point $x^{*}$ in $A$ which satisfies $d\left(x^{*}, T x^{*}\right)=d(A, B)$ is called a best proximity point of $T$ and the pair $\left(x^{*}, T x^{*}\right)$ is called best proximity pair of $T$. A best proximity point $x^{*}$ in $A$, indeed solves the following optimization problem:

$$
\min _{x \in A} d(x, T x) .
$$

\footnotetext{
*Corresponding author

Email addresses: alatif@kau.edu.sa (Abdul Latif), naeem.saleem2@gmail.com (Naeem Saleem), mujahid.abbas@up.ac.za (Mujahid Abbas)
}

doi:10.22436/jnsa.010.01.09 
The results which analyze the conditions under which the above optimization problem has a solution are known as Best proximity pair theorems. Clearly, if $A=B$, then best proximity point of $T$ becomes the solution of a fixed point equation $T x=x$. So, the best proximity point theorems generalize fixed point theorems in a natural way. For detailed discussion in this direction, we refer to [1, 3, 9, 12-14, 17-20, 22].

Vetro and Salimi [23] studied best proximity point theorems in the setup of non-Archimedean fuzzy metric spaces ( see also, $[2,17,18]$ ).

Let us first recall some basic definitions and known results needed in the sequel.

Definition $1.1([21])$. A binary operation $*:[0,1]^{2} \longrightarrow[0,1]$ is called a continuous t-norm if for any $x, y, w, z \in[0,1]$, the following conditions hold:

(1) $*$ is associative, commutative and continuous;

(2) $x * 1=x$;

(3) $w * x \leqslant y * z$ whenever $w \leqslant y$ and $x \leqslant z$.

Classical examples of continuous t-norm are: minimum $\wedge$, usual product $\cdot$ and Lukasiewicz $*_{\mathrm{L}} \mathrm{t}$ norm, where, $a \wedge b=\min \{a, b\}, a \cdot b=a b$, and $a *_{L} b=\max \{a+b-1,0\}$ for all $a, b \in[0,1]$.

It is easy to check that $*_{\mathrm{L}} \leqslant \cdot \leqslant \wedge$. In fact $* \leqslant \wedge$ for all continuous t-norm " $*$ " .

George and Veeramani $[5,6]$ modified the notion of fuzzy metric spaces with the help of a continuous t-norm by generalizing the concept of probabilistic metric space (see [11]) to a fuzzy situation.

Definition 1.2 (compare [6]). Let $X$ be a nonempty set, and " $*$ " a continuous t-norm. A fuzzy set $M$ on $X \times X \times[0, \infty)$ is said to be a fuzzy metric if for any $x, y, z \in X$, the following conditions hold:

(i) $M(x, y, t)>0$,

(ii) $x=y$ if and only if $M(x, y, t)=1$ for all $t>0$,

(iii) $M(x, y, t)=M(y, x, t)$,

(iv) $M(x, z, t+s) \geqslant M(x, y, t) * M(y, z, s)$ for all $t, s>0$,

(v) $M(x, y, \cdot):[0, \infty) \rightarrow[0,1]$ is left continuous.

The triplet $(X, M, *)$ is called a fuzzy metric space.

Since $M$ is a fuzzy set on $X^{2} \times[0, \infty), M(x, y, t)$ is regarded as the degree of closeness of $x$ and $y$ with respect to $t$.

It is well-known that for each $x, y \in X, M(x, y, \cdot)$ is a nondecreasing function on $(0, \infty)([7])$.

Lemma $1.3([7]) . \quad M$ is a continuous function on $\mathrm{X}^{2} \times(0, \infty)$.

Each fuzzy metric $M$ on $X$ generates Hausdorff topology $\tau_{M}$ whose base is the family of open $M-$ balls $\left\{B_{M}(x, \varepsilon, t): x \in X, \varepsilon \in(0,1), t>0\right\}$, where

$$
B_{M}(x, \varepsilon, t)=\{y \in X: M(x, y, t)>1-\varepsilon\} .
$$

Note that a sequence $\left\{x_{n}\right\}$ converges to $x \in X$ (with respect to $\tau_{M}$ ) if and only if $\lim _{n \rightarrow \infty} M\left(x_{n}, x, t\right)=1$ for all $t>0$.

Let $(X, d)$ be a metric space. Define $M_{d}: X \times X \times[0, \infty) \rightarrow[0,1]$ by

$$
M_{d}(x, y, t)=\frac{t}{t+d(x, y)}
$$

Then $\left(X, M_{d}, \cdot\right)$ is a fuzzy metric space and is called the standard fuzzy metric space induced by a metric $d$ ([5]). The topologies $\tau_{M_{d}}$ and $\tau_{d}$ (the topology induced by the metric $d$ ) on $X$ are the same. Note that if $d$ is a metric on a set $X$, then the fuzzy metric space $\left(X, M_{d}, *\right)$ is strong for every continuous $t$-norm "*" such that for all $* \leqslant \cdot$, where $M_{\mathrm{d}}$ is the standard fuzzy metric (see, [8]). 
A sequence $\left\{x_{n}\right\}$ in a fuzzy metric space $X$ is said to be a Cauchy sequence if for each $t>0$ and $\varepsilon \in(0,1)$, there exists $n_{0} \in \mathbb{N}$ such that $M\left(x_{n}, x_{m}, t\right)>1-\varepsilon$ for all $n, m \geqslant n_{0}$. A fuzzy metric space $X$ is complete ([6]) if every Cauchy sequence converges in $X$. A subset $A$ of $X$ is closed if for each convergent sequence $\left\{x_{n}\right\}$ in $A$ with $x_{n} \longrightarrow x$, we have $x \in A$. A subset $A$ of $X$ is compact if each sequence in $A$ has a convergent subsequence.

Throughout this paper, we assume that $A$ and $B$ are two nonempty subsets of a fuzzy metric space $(X, M, *)$.

Definition $1.4([17,23])$. Let $x \in X$ and $t>0$. Define $A_{0}(t)$ and $B_{0}(t)$ as follows:

$$
\begin{aligned}
& A_{0}(t)=\{x \in A: M(x, y, t)=M(A, B, t) \text { for some } y \in B\}, \text { and } \\
& B_{0}(t)=\{y \in B: M(x, y, t)=M(A, B, t) \text { for some } x \in A\},
\end{aligned}
$$

where,

$$
M(A, B, t)=\sup \{M(a, b, t): a \in A, b \in B\} .
$$

The distance of a point $x \in X$ from a nonempty set $A$ for $t>0$ is defined as

$$
M(x, A, t)=\sup _{a \in A} M(x, a, t), \text { for } t>0 .
$$

Definition 1.5 ([18]). A self-mapping $f$ on $A$ is said to be (a) fuzzy isometry if $M(f x, f y, t)=M(x, y, t)$ for all $x, y \in A$ and $t>0$ (b) fuzzy expansive if for any $x, y \in A$ and $t>0$, we have $M(f x, f y, t) \leqslant M(x, y, t)$.

Remark 1.6 ([18]). Note that every fuzzy isometry is fuzzy expansive but the converse does not hold in general.

Definition 1.7 ([18]). A set $B$ is said to be fuzzy approximately compact with respect to $A$ if for every sequence $\left\{y_{n}\right\}$ in $B$ and for some $x \in A, M\left(x, y_{n}, t\right) \longrightarrow M(x, B, t)$ implies that $x \in A_{0}(t)$.

Definition $1.8([18])$. A point $x$ in $A$ is said to be optimal coincidence point of the pair of mappings $(g, T)$, where $\mathrm{T}: \mathrm{A} \longrightarrow \mathrm{B}$ and $\mathrm{g}: \mathrm{A} \longrightarrow \mathrm{A}$ if

$$
M(g x, T x, t)=M(A, B, t)
$$

holds.

Lemma 1.9 ([17]). Let $\mathrm{T}: \mathrm{A} \rightarrow \mathrm{B}$. If for $\mathrm{t}>0, \mathrm{~A}_{0}(\mathrm{t}) \neq \emptyset$ and $\mathrm{T}\left(\mathrm{A}_{0}(\mathrm{t})\right) \subseteq \mathrm{B}_{0}(\mathrm{t})$. Then, there exists a sequence $\left\{x_{n}\right\} \subset A_{0}(t)$ such that

$$
M\left(x_{n+1}, T x_{n}, t\right)=M(A, B, t) \text { for all } n \in \mathbb{N} \text {. }
$$

Definition 1.10 ([17]). A sequence $\left\{x_{n}\right\} \subset A_{0}(t)$ satisfying condition (1.1) is called proximal fuzzy Picard sequence starting with $x_{0} \in A_{0}(t)$.

Definition 1.11 ([17]). A set $A_{0}(t)$ is fuzzy proximal T-orbitally complete if and only if every Cauchy proximal fuzzy Picard sequence in $A_{0}(t)$ starting with some $x_{0} \in A_{0}(t)$ converges to an element of $A_{0}(t)$.

Lemma 1.12 ([17]). Let $\mathrm{A}$ and $\mathrm{B}$ be nonempty closed subsets of a complete non-Archimedean fuzzy metric space $(\mathrm{X}, \mathrm{M}, *)$, if $\mathrm{A}_{0}(\mathrm{t}) \neq \emptyset$ and $\mathrm{B}$ is fuzzy approximately compact with respect to $\mathrm{A}$, then the set $\mathrm{A}_{0}(\mathrm{t})$ is closed.

Let $\Psi$ denote the set of all functions $\psi:[0,1] \rightarrow[0,1]$ satisfying the conditions (i) and (ii) given below.

(i) $\psi$ is continuous and strictly decreasing on $(0,1)$ with $\psi(t)>t$ and $\psi(t)=t$ if $t \in\{0,1\}$.

(ii) $\lim _{n \rightarrow \infty} \psi^{n}(t)=1$ if and only if $t=1$.

Definition 1.13. A mapping $\mathrm{T}: \mathrm{A} \longrightarrow \mathrm{B}$ is said to be a $\alpha$-proximal fuzzy contraction of type-I if there exists $\alpha \in[0,1]$ such that for any $u, v, x$ and $y$ in $A$, the following implication holds:

$$
\left.\begin{array}{l}
M(u, T x, t)=M(A, B, t) \\
M(v, T y, t)=M(A, B, t)
\end{array}\right\} \Longrightarrow M(u, v, t) \geqslant \psi\left([M(x, y, t)]^{\alpha}\right)
$$


Definition 1.14. Let $T: A \longrightarrow B$ and $g: A \rightarrow A$. A pair $\{g, T\}$ is said to be a $\alpha$-proximal fuzzy contraction of type-II if there exists $\alpha \in[0,1]$ for any $u, v, x$ and $y$ in $A$ satisfying

$$
\left.\begin{array}{l}
M(g u, T x, t)=M(A, B, t) \\
M(g v, T y, t)=M(A, B, t)
\end{array}\right\} \Longrightarrow M(g u, g v, t) \geqslant \psi\left([M(x, y, t)]^{\alpha}\right)
$$

For a self-mapping, an $\alpha$-proximal fuzzy contraction of type-II becomes Banach contractions. While a nonself-mapping is not necessarily a Banach's contraction mapping.

Note that if $\mathrm{gx}=\mathrm{I}_{\mathrm{A}}$, then every $\alpha$-proximal fuzzy contraction of type-II becomes $\alpha$-proximal fuzzy contraction of type-I.

The aim of this paper is to investigate the optimal coincidence point solution of a function $M(g x, T x, t)$ over a nonempty subset of fuzzy metric space, where $T: A \longrightarrow B$ is $\alpha$-proximal contraction mapping of type-I and type-II and $\mathrm{g}: A \rightarrow A$. Our results extend and generalize results in $[10,15]$ and $[16]$. We give some examples to illustrate our results and to compare the results in [10] and [15].

\section{Optimal coincidence point of $\alpha$-fuzzy proximal contraction mappings in non-Archimedean fuzzy metric spaces.}

We start with the following result.

Lemma 2.1. Let $A$ and $B$ be nonempty closed subsets of a complete non-Archimedean fuzzy metric space $(X, M, *)$, $\mathrm{T}: \mathrm{A} \rightarrow \mathrm{B}$ an $\alpha$-proximal fuzzy contraction of type-I and $\mathrm{A}_{0}(\mathrm{t}) \neq \emptyset$. Then $\mathrm{A}_{0}(\mathrm{t})$ is fuzzy proximal $\mathrm{T}$-orbitally complete provided that $\mathrm{T}\left(\mathrm{A}_{0}(\mathrm{t})\right) \subseteq \mathrm{B}_{0}(\mathrm{t})$ if $\mathrm{B}$ is approximately compact with respect to $\mathrm{A}$.

Proof. Let $x_{0}$ be a given point in $A_{0}(t)$ and $\left\{x_{n}\right\}$ a proximal fuzzy Picard sequence in $A_{0}(t)$ starting with $x_{0}$. As $(X, M, *)$ is complete and $A$ is closed, there exists an element $x^{*}$ in $A$ such that

$$
\lim _{n \rightarrow \infty} M\left(x_{n}, x^{*}, t\right)=1 .
$$

By Lemma 1.12, $A_{0}(t)$ is closed, indeed $A_{0}(t)$ is nonempty and $B$ is approximately compact with respect to $A$. Hence $x^{*} \in A_{0}(t)$.

Theorem 2.2. Let $\mathrm{g}: \mathrm{A} \rightarrow \mathrm{A}$ be a fuzzy expansive mapping and $\mathrm{T}: \mathrm{A} \rightarrow \mathrm{B}$ an $\alpha$-proximal fuzzy contraction of type-II with $\mathrm{T}\left(\mathrm{A}_{0}(\mathrm{t})\right) \subseteq \mathrm{B}_{0}(\mathrm{t})$ and $\mathrm{A}_{0}(\mathrm{t}) \subseteq \mathrm{g}\left(\mathrm{A}_{0}(\mathrm{t})\right)$ for any $\mathrm{t}>0$. If $\mathrm{B}$ is fuzzy approximately compact with respect to $A$, then the pair $(g, T)$ has a unique optimal coincidence point $x^{*}$ in $A_{0}(t)$.

Proof. Let $x_{0}$ be a given point in $A_{0}(t)$. As $T\left(A_{0}(t)\right) \subseteq B_{0}(t)$ and $A_{0}(t) \subseteq g\left(A_{0}(t)\right)$, we can choose an element $x_{1} \in A_{0}(t)$ such that $M\left(g x_{1}, T x_{0}, t\right)=M(A, B, t)$. From $T x_{1} \in T\left(A_{0}(t)\right) \subseteq B_{0}(t)$ and $A_{0}(t) \subseteq g\left(A_{0}(t)\right)$, it follows that there exists an element $x_{2} \in A_{0}(t)$ such that $M\left(g x_{2}, T x_{1}, t\right)=M(A, B, t)$. Continuing this way, we can obtain a sequence $\left\{x_{n}\right\}$ in $A_{0}(t)$ such that it satisfies

$$
M\left(g x_{n}, T x_{n-1}, t\right)=M(A, B, t) \text { and } M\left(g x_{n+1}, T x_{n}, t\right)=M(A, B, t) .
$$

As $\mathrm{T}$ is $\alpha$-proximal fuzzy contraction of type-II, and $\mathrm{g}$ is fuzzy expansive,

$$
\left.M\left(x_{n}, x_{n+1}, t\right) \geqslant M\left(g x_{n}, g x_{n+1}, t\right) \geqslant \psi\left[M\left(x_{n-1}, x_{n}, t\right)\right]^{\alpha}\right) \text { for all } n \in \mathbb{N} .
$$

If, $x_{n}=x_{n+1}$ holds for some $n \in \mathbb{N}$, then the result is obvious. Suppose that $x_{n} \neq x_{n+1}$, for all $n \in \mathbb{N}$. Note that

$$
M\left(x_{n}, x_{n+1}, t\right) \geqslant \psi\left(\left[M\left(x_{n-1}, x_{n}, t\right)\right]^{\alpha}\right) \geqslant \psi\left(M\left(x_{n-1}, x_{n}, t\right)\right)>M\left(x_{n-1}, x_{n}, t\right) .
$$

If we set $M\left(x_{n}, x_{n+1}, t\right)=\tau_{n}(t)$ for all $t>0, n \in \mathbb{N} \cup\{0\}$, then we have

$$
\tau_{n}(t) \geqslant \psi\left(\left[\tau_{n-1}(t)\right]^{\alpha}\right) \geqslant \psi\left(\tau_{n-1}(t)\right)>\tau_{n-1}(t) .
$$


That is, $\left\{\tau_{\mathfrak{n}}(t)\right\}$ is an increasing sequence for all $t>0$. Consequently, there exists $\tau(t) \leqslant 1$ such that $\lim _{n \rightarrow+\infty} \tau_{n}(t)=\tau(t)$. We claim that $\tau(t)=1$. Suppose not, there exists some $t_{0}>0$ such that $\tau\left(t_{0}\right)<1$. Also, $\tau_{n}\left(t_{0}\right) \leqslant \tau\left(t_{0}\right)$. On taking the limit as $n \rightarrow \infty$ on both sides of

$$
\tau_{n}(t) \geqslant \psi\left(\left[\tau_{n-1}(t)\right]^{\alpha}\right) \geqslant \psi\left(\tau_{n-1}(t)\right)>\tau_{n-1}(t),
$$

we have

$$
\tau\left(t_{0}\right) \geqslant \psi\left(\tau\left(t_{0}\right)\right)>\tau\left(t_{0}\right),
$$

a contradiction. Hence $\tau(t)=1$. Now we show that $\left\{x_{n}\right\}$ is a Cauchy sequence. Suppose to the contrary that $\left\{x_{n}\right\}$ is not a Cauchy sequence, there exist $\varepsilon \in(0,1)$ and $t_{0}>0$ such that for all $k \in \mathbb{N}$, there are $m_{k}, n_{k} \in \mathbb{N}$ with $m_{k}>n_{k} \geqslant k$ and

$$
M\left(x_{m_{k}}, x_{n_{k}}, t_{0}\right) \leqslant 1-\varepsilon .
$$

Assume that $m_{k}$ is the least integer exceeding $n_{k}$ for which the above inequality holds. Thus

$$
M\left(x_{m_{k}-1}, x_{n_{k}}, t_{0}\right)>1-\varepsilon .
$$

Note that, for all k, we have

$$
\begin{aligned}
1-\varepsilon & \geqslant M\left(x_{\mathfrak{m}_{k}}, x_{\mathfrak{n}_{k}}, t_{0}\right), \\
& \geqslant M\left(x_{m_{k}}, x_{m_{k}-1}, t_{0}\right) * M\left(x_{m_{k}-1}, x_{n_{k}}, t_{0}\right), \\
& >\tau_{m_{k}}\left(t_{0}\right) *(1-\varepsilon) .
\end{aligned}
$$

On taking limit as $k \rightarrow \infty$ on both sides of the above inequality, we obtain that $\lim _{k \rightarrow+\infty} M\left(x_{m_{k}}, x_{n_{k}}, t_{0}\right)=$ $1-\varepsilon$. Also,

$$
M\left(x_{m_{k}+1}, x_{n_{k}+1}, t_{0}\right) \geqslant M\left(x_{m_{k}+1}, x_{m_{k}}, t_{0}\right) * M\left(x_{m_{k}}, x_{n_{k}}, t_{0}\right) * M\left(x_{n_{k}}, x_{n_{k}+1}, t_{0}\right),
$$

and

$$
M\left(x_{m_{k}}, x_{n_{k}}, t_{0}\right) \geqslant M\left(x_{m_{k}}, x_{m_{k}+1}, t_{0}\right) * M\left(x_{m_{k}+1}, x_{n_{k}+1}, t_{0}\right) * M\left(x_{n_{k}+1}, x_{n_{k}}, t_{0}\right),
$$

imply that

$$
\lim _{k \rightarrow+\infty} M\left(x_{m_{k}+1}, x_{n_{k}+1}, t_{0}\right)=1-\varepsilon
$$

From (2.1), we obtain that

$$
M\left(g x_{m_{k}+1}, T x_{m_{k}}, t_{0}\right)=M\left(A, B, t_{0}\right) \text { and } M\left(g x_{n_{k}+1}, T x_{n_{k}}, t_{0}\right)=M\left(A, B, t_{0}\right) .
$$

Hence

$$
M\left(x_{m_{k}+1}, x_{n_{k}+1}, t_{0}\right) \geqslant M\left(g x_{m_{k}+1}, g x_{n_{k}+1}, t_{0}\right) \geqslant \psi\left(\left[M\left(x_{m_{k}}, x_{n_{k}}, t_{0}\right)\right]^{\alpha}\right) .
$$

On taking limit as $k \rightarrow \infty$ on both sides of the above inequality, we get that

$$
1-\varepsilon \geqslant \psi\left([1-\varepsilon]^{\alpha}\right) \geqslant \psi(1-\varepsilon)>1-\varepsilon,
$$

a contradiction. Hence $\left\{x_{n}\right\}$ is a Cauchy sequence. As $A_{0}(t)$ is T-orbitally complete (Lemma 2.1), the sequence $\left\{x_{n}\right\}$ converges to some element $x^{*}$ in $A_{0}(t)$, that is,

$$
\lim _{n \rightarrow \infty} M\left(x_{n}, x^{*}, t\right)=1 \text {. }
$$

Now

$$
M\left(g x^{*}, B, t\right) \geqslant M\left(g x^{*}, T x_{n}, t\right)
$$




$$
\begin{aligned}
& \geqslant M\left(g x^{*}, g x_{n+1}, t\right) * M\left(g x_{n+1}, T x_{n}, t\right) \\
& =M\left(g x^{*}, g x_{n+1}, t\right) * M(A, B, t) \\
& \geqslant M\left(g x^{*}, g x_{n+1}, t\right) * M\left(g x^{*}, B, t\right)
\end{aligned}
$$

implies that

$$
M\left(g x^{*}, B, t\right) \geqslant M\left(g x^{*}, T x_{n}, t\right) \geqslant M\left(g x^{*}, g x_{n+1}, t\right) * M\left(g x^{*}, B, t\right) .
$$

As $g$ is continuous, the sequence $\left\{g x_{n}\right\}$ converges to $g\left(x^{*}\right)$, and $M\left(g x^{*}, T x_{n}, t\right) \rightarrow M\left(g x^{*}, B, t\right)$. Since $B$ is a fuzzy approximately compact with respect to $A$, a sequence $\left\{T x_{n}\right\}$ in $B$ has a subsequence which converges to some $y$ in $B$, and $M\left(g x^{*}, y, t\right)=M(A, B, t)$, that is, $g x^{*} \in A_{0}(t)$. Since $A_{0} \subseteq g\left(A_{0}\right)$, there exists some $u \in A_{0}(t)$ such that

$$
M\left(g u, T x^{*}, t\right)=M(A, B, t)=M\left(g x_{n+1}, T x_{n}, t\right) \text { for all } n \in \mathbb{N} .
$$

As $\{g, T\}$ is $\alpha$-proximal fuzzy contraction of type-II and $g$ is a fuzzy expansive mapping, we have

$$
M\left(u, x_{n+1}, t\right) \geqslant M\left(g u, g x_{n+1}, t\right) \geqslant \psi\left(\left[M\left(x^{*}, x_{n}, t\right)\right]^{\alpha}\right) .
$$

Taking limit as $n \rightarrow \infty$ on both sides of the above inequality, we obtain that

$$
M\left(u, x^{*}, t\right) \geqslant \psi\left(\left[M\left(x^{*}, u, t\right)\right]^{\alpha}\right)
$$

and hence $M\left(u, x^{*}, t\right)=1$, which implies that $u=x^{*}$. Thus

$$
M\left(g x^{*}, T x^{*}, t\right)=M\left(g u, T x^{*}, t\right)=M(A, B, t)
$$

gives that $x^{*}$ is the optimal coincidence point of the pair $\{g, T\}$.

If there is another optimal coincidence point $y^{*}$ of the pair $\{g, T\}$ in $A_{0}(t)$, then we have

$$
M\left(g x^{*}, T x^{*}, t\right)=M(A, B, t) \text { and } M\left(g y^{*}, T y^{*}, t\right)=M(A, B, t) .
$$

Since $\{g, T\}$ is $\alpha$-proximal fuzzy contraction of type-II and $g$ is fuzzy expansive, so

$$
M\left(x^{*}, y^{*}, t\right) \geqslant M\left(g x^{*}, g y^{*}, t\right) \geqslant \psi\left(\left[M\left(x^{*}, y^{*}, t\right)\right]^{\alpha}\right),
$$

implies that $M\left(x^{*}, y^{*}, t\right)=1$ and $x^{*}=y^{*}$. Hence the optimal coincidence point of the pair $\{g, T\}$ is unique.

Corollary 2.3. If $\mathrm{T}: \mathrm{A} \rightarrow \mathrm{B}$ is an $\alpha$-proximal fuzzy contraction of type-I with $\mathrm{T}\left(\mathrm{A}_{0}(\mathrm{t})\right) \subseteq \mathrm{B}_{0}(\mathrm{t})$ for any $\mathrm{t}>0$, then $\mathrm{T}$ has a unique best proximity point $\mathrm{x}^{*}$ in $\mathrm{A}_{0}(\mathrm{t})$ provided that $\mathrm{B}$ is fuzzy approximately compact with respect to $A$.

Proof. Take $\mathrm{g}=\mathrm{I}_{\mathrm{A}}$ in Theorem 2.2.

Corollary 2.4. If $\mathrm{T}: \mathrm{A} \rightarrow \mathrm{B}$ is an $\alpha$-proximal fuzzy contraction of type-I with $\mathrm{T}\left(\mathrm{A}_{0}(\mathrm{t})\right) \subseteq \mathrm{B}_{0}(\mathrm{t})$ for any $\mathrm{t}>0$, then $\mathrm{T}$ has a unique best proximity point $\mathrm{x}^{*}$ in $\mathrm{A}_{0}(\mathrm{t})$ provided that $\mathrm{B}$ is fuzzy approximately compact with respect to A.

Proof. By Lemma 1.12, $A_{0}(t)$ is closed subset of complete non-Archimedean fuzzy metric space $(X, M, *)$ which implies that $A_{0}(t)$ is fuzzy proximal T-orbitally complete (Lemma 2.1). The result follows from Corollary 2.3.

Corollary 2.5. Let $\mathrm{g}: \mathrm{A} \rightarrow \mathrm{A}$ be a fuzzy isometric mapping and $\mathrm{T}: \mathrm{A} \rightarrow \mathrm{B}$ an $\alpha$-proximal fuzzy contraction of type-II with $\mathrm{T}\left(\mathrm{A}_{0}(\mathrm{t})\right) \subseteq \mathrm{B}_{0}(\mathrm{t})$ and $\mathrm{A}_{0}(\mathrm{t}) \subseteq \mathrm{g}\left(\mathrm{A}_{0}(\mathrm{t})\right)$ for any $\mathrm{t}>0$. If $\mathrm{B}$ is fuzzy approximately compact with respect to $A$, then the pair $(g, T)$ has a unique optimal coincidence point $x^{*}$ in $A_{0}(t)$. 
Corollary 2.6. Let $\mathrm{g}: \mathrm{A} \rightarrow \mathrm{A}$ be a fuzzy expansive mapping and $\mathrm{T}: \mathrm{A} \rightarrow \mathrm{B}$ with $\mathrm{A}_{0}(\mathrm{t}) \neq \phi, \mathrm{T}\left(\mathrm{A}_{0}(\mathrm{t})\right) \subseteq \mathrm{B}_{0}(\mathrm{t})$ and $A_{0}(t) \subseteq g\left(A_{0}(t)\right)$ for any $t>0$. If $B$ is fuzzy approximately compact with respect to $A$ and the pair $(g, T)$ satisfies the following implication

$$
\left.\begin{array}{l}
M(g u, T x, t)=M(A, B, t) \\
M(g v, T y, t)=M(A, B, t)
\end{array}\right\} \text { implies that } M(g u, g v, t) \geqslant \psi(M(x, y, t)),
$$

then the pair $(\mathrm{g}, \mathrm{T})$ has a unique optimal coincidence point $\mathrm{x}^{*}$ in $\mathrm{A}_{0}(\mathrm{t})$.

Proof. Following arguments similar to those in the proof of the Theorem 2.2 with $\alpha=1$, the result follows.

Remark 2.7. If $\mathrm{g}$ is isometry in Theorem 2.2, then we obtain Theorem 3.2 in ([15]).

Remark 2.8. If $\mathrm{g}=\mathrm{I}_{\mathrm{A}}$ in Definition 1.14, then we obtain Definition 3.1 in ([15]).

We now show that our result is proper generalization of the results in ([10], [15]).

Example 2.9. If $X=[0,1] \times \mathbb{R}, A=\{(0, x): x \geqslant 0$ and $x \in \mathbb{R}\}$ and $B=\{(1, y): y \geqslant 0$ and $y \in \mathbb{R}\}$, then

$$
M_{d}(A, B, t)=\frac{t}{t+1}, A_{0}(t)=\{(0,0)\} \text { and } B_{0}(t)=\{(1,0)\}
$$

Define the mappings $\mathrm{T}: \mathrm{A} \rightarrow \mathrm{B}$ and $\mathrm{g}: \mathrm{A} \rightarrow \mathrm{A}$ (a fuzzy expansive mapping) as:

$$
\mathrm{T}(\mathrm{x}, 0)=\left(1, \frac{\mathrm{x}}{4}\right) \text { and } \mathrm{g}(0, \mathrm{x})=4(0, \mathrm{x}) \text {. }
$$

Obviously, $T\left(A_{0}(t)\right)=B_{0}(t)$ and $A_{0}(t)=g\left(A_{0}(t)\right)$. Note that the points $u=\left(0, x_{1}\right), v=\left(0, x_{2}\right), x=\left(0, y_{1}\right)$ and $y=\left(0, y_{2}\right)$ in $A$ satisfy $M(g u, T x, t)=M(A, B, t)$ and $M(g v, T y, t)=M(A, B, t)$ if $x_{1}=\frac{y_{1}}{16}$ and $x_{2}=\frac{y_{2}}{16}$. Also, we have, $M(g u, g v, t) \geqslant \psi(M(x, y, t))$, where $\psi(t)=\sqrt{t}$. Thus all the conditions of the Corollary 2.6 are satisfied. Moreover, $(0,0)$ is an optimal coincidence point of $(g, T)$ in $A_{0}(t)$.

\section{Optimal coincidence point of $\alpha$-proximal fuzzy contraction in fuzzy metric spaces}

Lemma 3.1. Let $A$ and $B$ be nonempty subsets of a complete fuzzy metric space $(X, M, *), T: A \rightarrow B$ an $\alpha$-proximal fuzzy contraction of type-I and $\mathrm{A}_{0}(\mathrm{t})$ a nonempty closed subset of $\mathrm{A}$. Then $\mathrm{A}_{0}(\mathrm{t})$ is fuzzy proximal $\mathrm{T}$-orbitally complete provided that $\mathrm{T}\left(\mathrm{A}_{0}(\mathrm{t})\right) \subseteq \mathrm{B}_{0}(\mathrm{t})$.

Proof. Assume that $x_{0}$ be a given point in $A_{0}(t)$ and $\left\{x_{n}\right\}$ is a proximal fuzzy Picard sequence in $A_{0}(t)$ starting with $x_{0}$. As $(X, M, *)$ is complete and $A_{0}(t)$ is closed, there exists an element $x^{*}$ in $A_{0}(t)$ such that

$$
\lim _{n \rightarrow \infty} M\left(x_{n}, x^{*}, t\right)=1
$$

Theorem 3.2. Let $(A, B)$ be a pair of nonempty subset of a complete fuzzy metric space $(X, M, *), g: A \rightarrow A$ a fuzzy expansive and $\mathrm{T}: \mathrm{A} \rightarrow \mathrm{B}$ with $\mathrm{T}\left(\mathrm{A}_{0}(\mathrm{t})\right) \subseteq \mathrm{B}_{0}(\mathrm{t})$ and $\mathrm{A}_{0} \subseteq \mathrm{g}\left(\mathrm{A}_{0}\right)$. If the pair $\{\mathrm{g}, \mathrm{T}\}$ is an $\alpha$-proximal fuzzy contraction of type-II, then T has a unique best proximity point $x^{*}$ in $A_{0}(t)$ provided that $A_{0}(t)$ is closed and $B$ is a fuzzy approximately compact with respect to A.

Proof. Let $x_{0}$ be a given point in $A_{0}(t)$. By the following arguments similar to those in the proof of Theorem 2.2 , we obtain a sequence $\left\{x_{n}\right\}$ in $A_{0}(t)$ such that it satisfies

$$
M\left(g x_{n}, T x_{n-1}, t\right)=M(A, B, t), M\left(g x_{n+1}, T x_{n}, t\right)=M(A, B, t)
$$


and

$$
\lim _{n \rightarrow \infty} M\left(x_{n}, x_{n+1}, t\right)=\lim _{n \rightarrow \infty} \tau_{n}(t)=1 .
$$

Now we show that $\left\{x_{n}\right\}$ is a Cauchy sequence. Suppose to the contrary that $\left\{x_{n}\right\}$ is not a Cauchy sequence, there exist $\varepsilon \in(0,1)$ and $t_{0}>0$ such that for all $k \in \mathbb{N}$, there are $m_{k}, n_{k} \in \mathbb{N}$, with $m_{k}>n_{k} \geqslant k$ with

$$
M\left(x_{m_{k}}, x_{n_{k}}, t_{0}\right) \leqslant 1-\varepsilon .
$$

Assume that $m_{k}$ is the least integer exceeding $n_{k}$ which satisfies the above inequality, then

$$
M\left(x_{m_{k}-1}, x_{n_{k}}, t_{0}\right)>1-\varepsilon .
$$

Note that, for all k, we have

$$
\begin{aligned}
1-\varepsilon & \geqslant M\left(x_{m_{k}}, x_{n_{k}}, t_{0}\right), \\
& \geqslant M\left(x_{m_{k}}, x_{m_{k}}-1, \frac{t_{0}}{2}\right) * M\left(x_{m_{k}-1}, x_{n_{k}}, \frac{t_{0}}{2}\right), \\
& >\tau_{m_{k}}\left(\frac{t_{0}}{2}\right) *(1-\varepsilon) .
\end{aligned}
$$

On taking limit as $k \rightarrow \infty$ on both sides of the above inequality, we obtain that $\lim _{k \rightarrow \infty} M\left(x_{m_{k}}, x_{n_{k}}, t_{0}\right)=$ $1-\varepsilon$. Note that

$$
M\left(x_{m_{k}+1}, x_{n_{k}+1}, t_{0}\right) \geqslant M\left(x_{m_{k}+1}, x_{m_{k}}, \frac{t_{0}}{3}\right) * M\left(x_{m_{k}}, x_{n_{k}}, \frac{t_{0}}{3}\right) * M\left(x_{n_{k}}, x_{n_{k}+1}, \frac{t_{0}}{3}\right),
$$

and

$$
M\left(x_{m_{k}}, x_{n_{k}}, t_{0}\right) \geqslant M\left(x_{m_{k}}, x_{m_{k}+1}, \frac{t_{0}}{3}\right) * M\left(x_{m_{k}+1}, x_{n_{k}+1}, \frac{t_{0}}{3}\right) * M\left(x_{n_{k}+1}, x_{n_{k}}, \frac{t_{0}}{3}\right),
$$

imply that

$$
\lim _{k \rightarrow+\infty} M\left(x_{m_{k}+1}, x_{n_{k}+1}, t_{0}\right)=1-\varepsilon .
$$

From (3.1), we have

$$
M\left(g x_{m_{k}+1}, T x_{m_{k}}, t_{0}\right)=M\left(A, B, t_{0}\right) \text { and } M\left(g x_{n_{k}+1}, T x_{n_{k}}, t_{0}\right)=M\left(A, B, t_{0}\right) .
$$

Thus

$$
M\left(x_{m_{k}+1}, x_{n_{k}+1}, t_{0}\right) \geqslant M\left(g x_{m_{k}+1}, g x_{n_{k}+1}, t_{0}\right) \geqslant \psi\left(\left[M\left(x_{m_{k}}, x_{n_{k}}, t_{0}\right)\right]^{\alpha}\right) .
$$

On taking limit as $k \rightarrow \infty$ on both sides of the above inequality, we get that

$$
1-\varepsilon \geqslant \psi\left([1-\varepsilon]^{\alpha}\right) \geqslant \psi(1-\varepsilon)>1-\varepsilon,
$$

a contradiction. Hence $\left\{x_{n}\right\}$ is a Cauchy sequence. Since $A_{0}(t)$ is closed, the sequence $\left\{x_{n}\right\}$ converges to some element $x^{*}$ in $A_{0}(t)$

$$
\lim _{n \rightarrow \infty} M\left(x_{n}, x^{*}, t\right)=1 .
$$

Now

$$
M\left(g x^{*}, B, t\right) \geqslant M\left(g x^{*}, T x_{n}, t\right) \geqslant M(A, B, t) \geqslant M\left(g x^{*}, B, t\right)
$$

implies that

$$
M\left(g x^{*}, B, t\right) \geqslant M\left(g x^{*}, T x_{n}, t\right) \geqslant M\left(g x^{*}, B, t\right) .
$$

As $g$ is continuous and the sequence $\left\{x_{n}\right\}$ converges to $x^{*}$, the sequence $\left\{g x_{n}\right\}$ converges to $g\left(x^{*}\right)$, $M\left(g x^{*}, T x_{n}, t\right) \rightarrow M\left(g x^{*}, B, t\right)$. The rest of the proof follows on the similar lines in the proof of Theorem 2.2.

Example 3.3. Let $X=[0,1] \times \mathbb{R}$ and $A=\left\{(0, x)\right.$ : for all $\left.x \in \mathbb{R}^{+} \cup\{0\}\right\}$ and $B=\left\{(1, y)\right.$ : for all $\left.y \in \mathbb{R}^{+} \cup\{0\}\right\}$. Then

$$
A_{0}(t)=A \text { and } B_{0}(t)=B
$$


Let

$$
M(x, y, t)=e^{-\frac{d(x, y)}{t}} \text { for all } t>0,
$$

where $d(x, y)=\left|x_{1}-y_{1}\right|+\left|x_{2}-y_{2}\right|$ for all $x=\left(x_{1}, y_{1}\right), y=\left(x_{2}, y_{2}\right)$ in $X$. Note that, $M(A, B, t)=e^{-\frac{1}{t}}$. Define the mappings $\mathrm{T}: \mathrm{A} \rightarrow \mathrm{B}$ and $\mathrm{g}: \mathrm{A} \rightarrow \mathrm{A}$ as:

$$
\mathrm{T}(0, x)=\left(1, \frac{x}{4}\right) \text {, and } g(0, x)=(0,2 x) .
$$

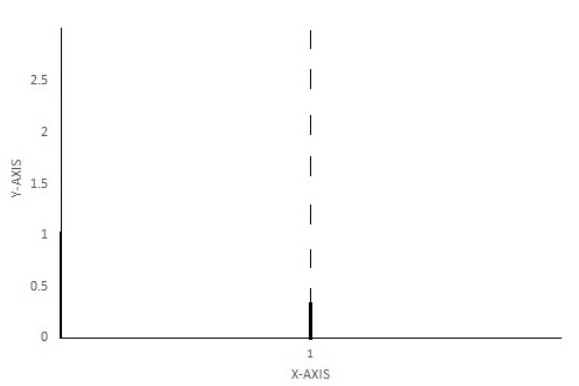

Figure 1

Note that $\mathrm{T}\left(\mathrm{A}_{0}(\mathrm{t})\right) \subseteq \mathrm{B}_{0}(\mathrm{t})$, and the points $u=(0, a), v=(0, b), x=(0, c)$ and $y=(0, d) \in A$ satisfy

$$
M(g u, T x, t)=M(A, B, t) \text {, and } M(g v, T y, t)=M(A, B, t),
$$

where $a=\frac{c}{8}$, and $b=\frac{d}{8}$. Also,

$$
M(g u, g v, t) \geqslant \psi\left([M(x, y, t)]^{\alpha}\right)
$$

holds true with $\psi(t)=\sqrt{t}$. Hence pair $\{g, T\}$ satisfies all conditions of Theorem 3.2. Moreover, $(0,0)$ is the unique $\alpha$-optimal best proximity point of the pair $\{g, T\}$.

Remark 3.4. Note that, Theorem 3.2 in [15] does not hold in this setup. As, every fuzzy expansive mapping is fuzzy isometry, hence Theorem 3.2 is a proper generalization of Theorem 3.2 in [15].

Note that, if the mapping $g$ in Theorem 3.2 is a fuzzy isometry instead of fuzzy expansive, then we obtain the following result.

Theorem 3.5. Let $(A, B)$ be a pair of nonempty subset of a complete fuzzy metric space $(X, M, *), g: A \rightarrow A$ a fuzzy isometry and $\mathrm{T}: \mathrm{A} \rightarrow \mathrm{B}$ with $\mathrm{T}\left(\mathrm{A}_{0}(\mathrm{t})\right) \subseteq \mathrm{B}_{0}(\mathrm{t})$ and $\mathrm{A}_{0} \subseteq \mathrm{g}\left(\mathrm{A}_{0}\right)$. If the pair $\{\mathrm{g}, \mathrm{T}\}$ is an $\alpha$-proximal fuzzy contraction of type-II, then $T$ has a unique best proximity point $x^{*}$ in $A_{0}(t)$ provided that $A_{0}(t)$ is closed and $B$ is a fuzzy approximately compact with respect to A.

Proof. It follows from Remark 1.6 and Theorem 3.2.

An example is provided to show that our result also holds in the setting of [15].

Example 3.6. If $X=[0,1] \times \mathbb{R}$ and $A=\{(0, x)$ : for all $x \in \mathbb{R}\}$ and $B=\{(1, y)$ : for all $y \in \mathbb{R}\}$, then

$$
A_{0}(t)=A \text { and } B_{0}(t)=B \text {. }
$$

Let

$$
M(x, y, t)=e^{-\frac{d(x, y)}{t}} \text { for all } t>0,
$$

where $d(x, y)=\left|x_{1}-y_{1}\right|+\left|x_{2}-y_{2}\right|$ for all $x=\left(x_{1}, y_{1}\right), y=\left(x_{2}, y_{2}\right)$ in $X$. Note that, $M(A, B, t)=e^{-\frac{1}{t}}$. Define the mappings $\mathrm{T}: \mathrm{A} \rightarrow \mathrm{B}$ and $\mathrm{g}: \mathrm{A} \rightarrow \mathrm{A}$ as:

$$
\mathrm{T}(0, x)=\left(1, \frac{x}{4}\right) \text { and } g(0, x)=(0,-x) .
$$


Note that $T\left(A_{0}(t)\right) \subseteq B_{0}(t)$ and the points $u=(0, a), v=(0, b), x=(0, c)$ and $y=(0, d) \in A$ satisfy

$$
M(g u, T x, t)=M(A, B, t) \text {, and } M(g v, T y, t)=M(A, B, t),
$$

where $a=\frac{-c}{4}$, and $b=\frac{-d}{4}$. Also,

$$
M(g u, g v, t) \geqslant \psi\left([M(x, y, t)]^{\alpha}\right)
$$

holds with $\psi(t)=\sqrt{t}$. Hence pair $\{g, T\}$ satisfies all conditions of Theorem 3.5. Moreover, $(0,0)$ is the unique $\alpha$-optimal best proximity point of the pair $\{\mathrm{g}, \mathrm{T}\}$.

Corollary 3.7. Let $(A, B)$ be a pair of nonempty subsets of a complete fuzzy metric space $(X, M, *), g$ a fuzzy expansive mapping on $\mathrm{A}, \mathrm{T}: \mathrm{A} \rightarrow \mathrm{B}, \mathrm{A}_{0}(\mathrm{t})$ a closed and fuzzy proximal $\mathrm{T}$-orbitally complete with $\mathrm{T}\left(\mathrm{A}_{0}(\mathrm{t})\right) \subseteq$ $\mathrm{B}_{0}(\mathrm{t})$. If the following implication holds:

$$
\left.\begin{array}{l}
M(g u, T x, t)=M(A, B, t) \\
M(g v, T y, t)=M(A, B, t)
\end{array}\right\} \Longrightarrow M(g u, g v, t) \geqslant \psi[M(x, y, t)]
$$

then, a pair $\{\mathrm{g}, \mathrm{T}\}$ has a unique best proximity point $\mathrm{x}^{*}$ in $\mathrm{A}_{0}(\mathrm{t})$ provided that $\mathrm{B}$ is a fuzzy approximately compact with respect to $A$.

Proof. The pair of mapping $\{\mathrm{g}, \mathrm{T}\}$ satisfies all the conditions of Theorem 3.2 with $\alpha=1$. The result then follows from Theorem 3.2.

Theorem 3.8. Let $(A, B)$ be a pair of nonempty subset of a complete fuzzy metric space $(X, M, *)$ and $T: A \rightarrow B$ an $\alpha$-proximal fuzzy contraction of type-I with $\mathrm{T}\left(\mathrm{A}_{0}(\mathrm{t})\right) \subseteq \mathrm{B}_{0}(\mathrm{t})$. Then $\mathrm{T}$ has a unique best proximity point $\mathrm{x}^{*}$ in $A_{0}(t)$ provided that $A_{0}(t)$ is closed and $B$ is a fuzzy approximately compact with respect to $A$.

Proof. Take $\mathrm{g}=\mathrm{I}_{\mathrm{A}}$ (the identity mapping) in the proof of Theorem 3.2.

Example 3.9. Let $X=[0,1] \times \mathbb{R}$ and $A=\{(0, x): 0 \leqslant x \leqslant 1, x \in \mathbb{R}\}$ and $B=\{(1, y): 0 \leqslant y \leqslant 1, y \in \mathbb{R}\}$. Then

$$
A_{0}(t)=A \text { and } B_{0}(t)=B .
$$

Let

$$
M(x, y, t)=e^{-\frac{d(x, y)}{t}} \text { for all } t>0,
$$

where $d(x, y)=\left|x_{1}-y_{1}\right|+\left|x_{2}-y_{2}\right|$ for all $x=\left(x_{1}, y_{1}\right), y=\left(x_{2}, y_{2}\right)$ in $X$. Note that, $M(A, B, t)=e^{-\frac{1}{t}}$. Define the mapping $\mathrm{T}: \mathrm{A} \rightarrow \mathrm{B}$ by

$$
\mathrm{T}(0, x)=\left(1, \frac{x}{4}\right)
$$

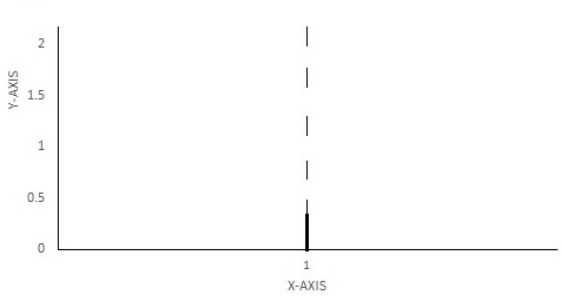

Figure 2

Note that $T\left(A_{0}(t)\right) \subseteq B_{0}(t)$ and the points $u=(0, a), v=(0, b), x=(0, c)$ and $y=(0, d) \in A$ satisfy

$$
M(u, T x, t)=M(A, B, t) \text { and } M(v, T y, t)=M(A, B, t),
$$

where $a=\frac{c}{4}$, and $b=\frac{d}{4}$. Also,

$$
M(u, v, t) \geqslant \psi\left([M(x, y, t)]^{\alpha}\right)
$$

holds true where $\psi(t)=\sqrt{t}$. Thus, all the conditions of Corollary 3.8 are satisfied. Moreover, $(0,0)$ is the unique best proximity point of $\mathrm{T}$. 
Remark 3.10. Definition 1.13 reduces to Definition 3.1 in [15] only when $\psi(t)=t$. Thus, our results extend and generalize the results in [15].

Corollary 3.11. Let $(A, B)$ be a pair of nonempty subset of a complete fuzzy metric space $(X, M, *)$ such that $A_{0}(t)$ is a fuzzy proximal T-orbitally complete. If $\mathrm{T}: \mathrm{A} \rightarrow \mathrm{B}$ satisfies the following implication

$$
\left.\begin{array}{l}
M(u, T x, t)=M(A, B, t) \\
M(v, T y, t)=M(A, B, t)
\end{array}\right\} \Longrightarrow M(u, v, t) \geqslant \psi[M(x, y, t)]
$$

then $\mathrm{T}$ has a unique best proximity point $x^{*}$ in $\mathrm{A}_{0}(\mathrm{t})$ provided that $\mathrm{A}_{0}(\mathrm{t})$ is closed, $\mathrm{B}$ is a fuzzy approximately compact with respect to $A$ and $\mathrm{T}\left(\mathrm{A}_{0}(\mathrm{t})\right) \subseteq \mathrm{B}_{0}(\mathrm{t})$.

Proof. The mapping T satisfies all condition of Theorem 3.2 with $\alpha=1$. Also, if $g=I_{A}$ (identity mapping on A). The result follows from Theorem 3.2.

Corollary 3.12. Let $(A, B)$ be a pair of nonempty subset of a complete fuzzy metric space $(X, M, *), g$ is fuzzy isometry on $\mathrm{A}$ and $\mathrm{T}: \mathrm{A} \rightarrow \mathrm{B}$ with $\mathrm{T}\left(\mathrm{A}_{0}(\mathrm{t})\right) \subseteq \mathrm{B}_{0}(\mathrm{t})$. If the pair $\{\mathrm{g}, \mathrm{T}\}$ is an $\alpha$-proximal fuzzy contraction of type-II, then the pair has a unique best proximity point $x^{*}$ in $A_{0}(t)$ provided that $A_{0}(t)$ is fuzzy proximal T-orbitally complete.

Proof. The result follows from Theorem 3.2.

Corollary 3.13. Let $(\mathrm{A}, \mathrm{B})$ be a pair of nonempty closed subset of a complete fuzzy metric space $(X, M, *)$. If $\mathrm{T}: \mathrm{A} \rightarrow \mathrm{B}$ satisfies the following implication

$$
\left.\begin{array}{l}
M(u, T x, t)=M(A, B, t) \\
M(v, T y, t)=M(A, B, t)
\end{array}\right\} \Longrightarrow M(u, v, t) \geqslant \psi[M(x, y, t)]
$$

then $\mathrm{T}$ has a unique best proximity point $\mathrm{x}^{*}$ in $\mathrm{A}_{0}(\mathrm{t})$ provided that $\mathrm{A}_{0}(\mathrm{t})$ is fuzzy proximal $\mathrm{T}$-orbitally complete and $\mathrm{T}\left(\mathrm{A}_{0}(\mathrm{t})\right) \subseteq \mathrm{B}_{0}(\mathrm{t})$.

Proof. Proof of this corollary is on the same lines as proof of Theorem 3.2.

\section{Acknowledgment}

This article was funded by the Deanship of Scientific Research (DSR), King Abdulaziz University, Jeddah. The authors, therefore, acknowledge with thanks DSR for the technical and financial support.

We appreciate the reviewers careful reading and remarks which helped us to improve the presentation of the paper.

\section{References}

[1] M. Abbas, N. Saleem, M. De la Sen, Optimal coincidence point results in partially ordered non-Archimedean fuzzy metric spaces, Fixed Point Theory Appl., 2016 (2016), 18 pages. 1

[2] M. De la Sen, M. Abbas, N. Saleem, On optimal fuzzy best proximity coincidence points of fuzzy order preserving proximal $\Psi(\sigma, \alpha)$-lower-bounding asymptotically contractive mappings in non-Archimedean fuzzy metric spaces, SpringerPlus, 5 (2016), 26 pages. 1

[3] A. A. Eldred, P. Veeramani, Existence and convergence of best proximity points, J. Math. Anal. Appl., 323 (2006), 1001-1006. 1

[4] K. Fan, Extensions of two fixed point theorems of F. E. Browder, Math. Z., 112 (1969), 234-240. 1

[5] A. George, P. Veeramani, On some results in fuzzy metric spaces, Fuzzy Sets and Systems, 64 (1994), 395-399. 1, 1

[6] A. George, P. Veeramani, On some results of analysis for fuzzy metric spaces, Fuzzy Sets and Systems, 90 (1997), 365-368. 1, 1.2, 1

[7] M. Grabiec, Fixed points in fuzzy metric spaces, Fuzzy Sets and Systems, 27 (1988), 385-389. 1, 1.3

[8] J. Gutiérrez García, S. Romaguera, Examples of non-strong fuzzy metrics, Fuzzy Sets and Systems, 162 (2011), 91-93. 1 
[9] N. Hussain, A. Latif, P. Salimi, Best proximity point results for modified Suzuki $\alpha$ - $\psi$-proximal contractions, Fixed Point Theory Appl., 2014 (2014), 16 pages. 1

[10] M. Jleli, B. Samet, An optimization problem involving proximal quasi-contraction mappings, Fixed Point Theory Appl., 2014 (2014), 12 pages. 1, 2

[11] I. Kramosil, J. Michálek, Fuzzy metric and statistical metric spaces, Kybernetika (Prague), 11 (1975), 326-334. 1

[12] A. Latif, M. Hezarjaribi, P. Salimi, N. Hussain, Best proximity point theorems for $\alpha-\psi-$ proximal contractions in intuitionistic fuzzy metric spaces, J. Inequal. Appl., 2014 (2014), 19 pages. 1

[13] A. Latif, A. Ninsri, W. Sintunavarat, The $(\alpha, \beta)$-generalized convex contractive condition with approximate fixed point results and some consequence, Fixed Point Theory Appl., 2016 (2016), 14 pages.

[14] C. Mongkolkeha, Y. J. Cho, P. Kumam, Best proximity points for generalized proximal C-contraction mappings in metric spaces with partial orders, J. Inequal. Appl., 2013 (2013), 12 pages. 1

[15] C. Mongkolkeha, W. Sintunavarat, Best proximity points for multiplicative proximal contraction mapping on multiplicative metric spaces, J. Nonlinear Sci. Appl., 8 (2016), 1134-1140. 1, 2.7, 2.8, 2, 3.4, 3, 3.10

[16] M. Ozavsar, A. C. Cevikel, Fixed points of multiplicative contraction mappings on multiplicative metric spaces, ArXiv, 2012 (2012), 14 pages. 1

[17] Z. Raza, N. Saleem, M. Abbas, Optimal coincidence points of proximal quasi-contraction mappings in non-Archimedean fuzzy metric spaces, J. Nonlinear Sci. Appl., 9 (2016), 3787-3801. 1, 1.4, 1.9, 1.10, 1.11, 1.12

[18] N. Saleem, M. Abbas, Z. Raza, Optimal coincidence best approximation solution in non-Archimedean fuzzy metric spaces, Iran. J. Fuzzy Syst., 13 (2016), 113-124. 1, 1.5, 1.6, 1.7, 1.8

[19] N. Saleem, B. Ali, M. Abbas, Z. Raza, Fixed points of Suzuki type generalized multivalued mappings in fuzzy metric spaces with applications, Fixed Point Theory Appl., 2015 (2015), 18 pages.

[20] V. Sankar Raj, P. Veeramani, Best proximity pair theorems for relatively nonexpansive mappings, Appl. Gen. Topol., 10 (2009), 21-28. 1

[21] B. Schweizer, A. Sklar, Statistical metric spaces, Pacific J. Math., 10 (1960), 313-334. 1.1

[22] T. Suzuki, M. Kikkawa, C. Vetro, The existence of best proximity points in metric spaces with the property UC, Nonlinear Anal., 71 (2009), 2918-2926. 1

[23] C. Vetro, P. Salimi, Best proximity point results in non-Archimedean fuzzy metric spaces, Fuzzy Inf. Eng., 5 (2013), 417429. $1,1.4$ 